\title{
Etoposide-induced Smad6 expression is required for the G1 to $S$ phase transition of the cell cycle in CMT-93 mouse intestinal epithelial cells
}

\author{
Youn Sook Lee ${ }^{1 *}$, Eun Kyung Lee ${ }^{2 *}$, \\ Inn-Oc Han $^{2}$ and Seok Hee Park ${ }^{1,2,3}$ \\ ${ }^{1}$ Department of Biological Science \\ Sungkyunkwan University \\ Suwon 440-746, Korea \\ ${ }^{2}$ Inha University College of Medicine \\ Incheon 400-121, Korea \\ ${ }^{3}$ Corresponding author: Tel, 82-31-290-5912; \\ Fax, 82-31-290-7015; E-mail, parks@ skku.edu \\ *These authors contributed equally to this work.
}

Accepted 27 November 2007

Abbreviations: BMP, bone morphogenic protein; BrdU, bromodeoxyuridine; DDRE-S6, DNA damage-responsible element in the Smad6; DSB, double strand break; TPA, 12-O-tetradecanoyl phorbol-13-acetate

\begin{abstract}
The inhibitory Smad6 and Smad7 are responsible for cross-talk between TGF- $\beta$ /bone morphogenic protein (BMP) signaling and other cellular signaling pathways, as well as negative feedback on their own signaling functions. Although inhibitory Smads are induced by various stimuli, little is known about the stimuli that increase Smad6 transcription, in contrast to Smad7. Here we demonstrate that etoposide, which induces double strand breaks during DNA replication, significantly up-regulates the transcription of the Smad6 gene in CMT-93 mouse intestinal cells by increasing specific DNA binding proteins. In addition, endogenous inhibition of the Smad6 gene by RNAi interference led to transient accumulation of G1 phase cells and reduction in incorporation of bromodeoxyuridine (BrdU). These findings strongly suggest that Smad6 plays a distinct role in the signaling of etoposide-induced DNA damage.
\end{abstract}

Keywords: cell cycle; DNA damage; etoposide; Smad6 protein; transforming growth factor $\beta$

\section{Introduction}

Among the proteins involved in TGF- $\beta /$ bone mor- phogenic protein (BMP) signaling pathways, much attention has been paid to the inhibitory Smads (I-Smads), Smad6 and Smad7. Inhibitory Smads act as major negative regulators, forming autoinhibitory feedback loops on TGF- $\beta$ /BMP signaling (Hayashi et al., 1997; Imamura et al., 1997; Nakao et al., 1997). Extensive studies have shown that the effects of I-Smads in negative regulation of TGF- $\beta$ /BMP signals are facilitated by HECT type E3 ubiquitin ligases, Smurf1 and Smurf2 (Kavsak et al., 2000; Ebisawa et al., 2001; Murakami et al., 2003). Smad7 interacts with Smurf1 and Smurf2, recruiting them into TGF- $\beta$ type I receptors (T $\beta R \mathrm{RI}$ ), and induces the degradation of activated $T \beta R I$ (Kavsak et al., 2000; Ebisawa et al., 2001). In addition, it has been reported that Smurf1 induces degradation of BMP-activated Smads indirectly through I-Smads (Murakami et al., 2003).

However, the most interesting feature of I-Smads is that their expression is transcriptionally induced by various extracellular stimuli as well as by TGF- $\beta$ or BMP, allowing them to act as mediators of cross-talk with other signaling pathways (Park, 2005). Pro-inflammatory stimuli, such as IFN- $\gamma$ and TNF- $\alpha$ increase the expression of the Smad7 gene through activation of STAT1 and RelA, resulting in down-regulation of TGF- $\beta$ signaling (Ulloa et al., 1999; Bitzer et al., 2000). The activation of CD40 induces Smad7 expression through NF-KB to suppress TGF- $\beta$-mediated growth inhibition and apoptosis in B-lymphocytes (Patil et al., 2000). In contrast with Smad7, little is known about extracellular stimuli that increase the expression of Smad6 and its interconnection with other signaling pathways. Reports have shown that expression of Smad6 is induced by laminar shear stress in vascular endothelial cells (Topper et al., 1997) and that 12-O-tetradecanoylphorbol-13-acetate (TPA) down-regulates Smad6 mRNA (Tsunobuchi et al., 2004). How the modulation of Smad6 expression by these stimuli affects other cellular signaling pathways remains unknown. A distinct role of Smad6 in mediating the cross-talk between the TGF- $\beta$ /BMP signal and other cellular signals has been proposed recently by Choi et al. (2006), who demonstrated that Smad6, induced by TGF- $\beta$ or BMP, negatively regulates interleukin-1 receptor/ Toll-like Receptor signaling.

Here we show that Smad6 expression is trans- 
iently induced at the transcriptional level by etoposide treatment, which causes double-stranded DNA breaks (Robert and Larsen, 1998). We also reveal that the increased expression of the Smad6 gene resulting from etoposide treatment is required for the $\mathrm{G} 1$ to $S$ phase transition of the cell cycle. Thus we suggest that Smad6 is involved in the signaling of etoposide-induced DNA damage and plays an important role in the early cellular responses induced by DNA damage.

\section{Materials and Methods}

\section{Plasmids}

Serial deletion mutants of the Smad6 promoter $(-9.5 \mathrm{k} /-1,035,-6.6 \mathrm{k} /-1,035,-3,213 /-1.035,-1,911 /$ $-1,035,-1,696 /-1,035$, and $-1,153 /-1,035)$ in the pGL2-Basic vector were kindly provided by $\mathrm{Dr}$. Miyazono (University of Tokyo, Japan) (Ishida et al., 2000). Subdivided deletion mutants $(-1,860 /$ $-1,035$; S6-4-1, -1,812/-1,035; S6-4-2, and -1,760/ $-1,035$; S6-4-3) were generated by inserting the amplified DNAs into Kpnl/ Xhol sites of the pGL2Basic vector (Promega, Madison, WI), respectively. Each double-stranded oligonucleotide, corresponding to the regions from $-1,812$ to -(DDRE-S6), $-1,812$ to $-1,787$ (L region), and $-1,786$ to -1761 ( $R$ region), was cloned into $\mathrm{Kpnl/BamHI}$ sites of pGL2-pro vector (Promega). The sequences of newly designed reporter plasmids were verified by DNA sequencing.

\section{Reagents and antibodies}

Etoposide was purchased from Sigma (St. Louis, $\mathrm{MO})$; the working concentration of etoposide was empirically optimized at $25 \mu \mathrm{M}$ for this study. The reagents for cell culture were obtained from GIBCO-BRL (Gaithersburg, MD). Antibodies against Smad6 and p21 protein were obtained from Zymed Laboratories (South San Franscisco, CA) and Santa Cruz Biotechnology (Santa Cruz, CA). Secondary HRP conjugated anti-rabbit or anti-mouse antibodies were purchased from Zymed laboratories. Western blotting detection kits were purchased from Amersham Bioscience (Piscataway, NJ).

\section{Cell lines, western blot analysis, transient transfection, and reporter assay}

CMT-93 mouse intestinal epithelial cells were purchased from the American Type Culture Collection (Rockville, MD) and maintained in DMEM supplemented with $10 \% \mathrm{FBS}$ at $37^{\circ} \mathrm{C}$ in a humidified environment containing $5 \% \mathrm{CO}_{2}$. siRNA-mediated
Smad6-knock down CMT-93 cells (CMT-93-siS6) and control CMT-93 cells with pU6PL vector (CMT93-pU6PL) were prepared as previously described (Choi et al., 2006). Preparation of whole cell extracts and western blot analysis were performed as previously described (Lee et al., 2007a). The cells in each 6-well plate were transiently transfected with the indicated plasmids using Effectene (Qiagen, Uppsala, Sweden) according to the manufacturer's protocol. After $24 \mathrm{~h}$, cells were treated with $25 \mu \mathrm{M}$ etoposide and cultured for the indicated times. Luciferase activities were measured using the dual luciferase reporter system (Promega). All experiments were repeated at least three times with similar results. Activities were normalized on the basis of Renilla luciferase expression from TK-Renilla plasmids according to the manufacturer's protocol.

\section{RNA extraction and quantitative real time PCR}

Total RNA extraction was performed as previously described (Choi et al., 2006). An iCycler real-time PCR machine and $\mathrm{iQ}$ SYBR Green Supermix (Bio-Rad, Hercules, CA) were used for quantitative RT-PCR amplifications of Smad6 and GAPDH genes under the following conditions: 40 cycles of $95^{\circ} \mathrm{C}$ for $40 \mathrm{~s}, 55^{\circ} \mathrm{C}$ for $30 \mathrm{~s}$, and $72^{\circ} \mathrm{C}$ for $1 \mathrm{~min}$. $\mathrm{A}$ dilution series of the plasmid standard for each gene was used for quantification of the PCR product. For normalization of the cycling threshold values obtained with the experimental samples, GAPDH was amplified under the same conditions. All reactions were repeated at least three times independently and the results are shown as means $\pm \mathrm{SD}$. The primer sequences were as follows: Smad6, 5'-TGGTGCAGCGTGGCGTAC-3' and 5'CTATCTGTGGTTGTTGAATA-3'; GAPDH, 5'-AATGTGTCCGTCGTGGATCT-3' and 5'-TCCACCACCCTGTTGCTGTA-3'.

\section{Preparation of nuclear extracts and electrophoretic mobility shift assay (EMSA)}

CMT-93 cells, treated or not treated with etoposide, were cultured in DMEM medium with $10 \%$ FBS. The preparation of nuclear extracts and EMSA was performed essentially as described (Park et al., 2001). For EMSA, double-stranded oligonucleotides containing either DDRE-S6, $L$ region or $R$ region were labeled with $\left[\gamma_{-}{ }^{32}\right.$ P]ATP and polynucleotide kinase. The oligonucleotide sequences were as follows: DDRE-S6, 5'-ATAACTGGGGAAAGCACGCCCCTCTATCACTCTCGAAGGGGCAT AAGGTAAA-3'; L region, 5'-ATAACTGGGGAAAGCACGCCCCTCTA-3'; R region, 5'-TCACTCTCGAAGGGGCATAAGGTAAA-3'. 


\section{Cell cycle analysis and double thymidine block}

Cell cycle analysis and double thymidine block were performed as previously described (Kwak et al., 2005; Lee et al., 2006). Briefly, cells were harvested and fixed with $100 \%$ methanol for cell cycle analysis. After washing with PBS, cells were stained with $50 \mu \mathrm{g} / \mathrm{ml}$ propidium iodide (Sigma) in the presence of $60 \mu \mathrm{g} / \mathrm{ml}$ RNase $A$ and incubated at room temperature in the dark for $30 \mathrm{~min}$. The samples were analyzed using a flow cytometer (Beckman Coulter, Fullerton, CA) according to the manufacturer's instructions. For synchronization, cells were treated with $2 \mathrm{mM}$ thymidine for $16 \mathrm{~h}$, released into regular medium for $8 \mathrm{~h}$, then retreated with $2 \mathrm{mM}$ thymidine for $16 \mathrm{~h}$, and released into $25 \mu \mathrm{M}$ etoposide. At the indicated time points, cells were harvested and stained with propidium iodide.

\section{BrdU incorporation}

The BrdU cell proliferation assay (Calbiochem, Darmstadt, Germany) was performed as previously described (Lee et al., 2007b). Briefly, Smad6-knock- down CMT-93 cells (CMT-93-siS6) and Smad6expressing CMT-93 cells (CMT-93-pU6PL) were cultured in 6-well plates; the medium was replaced with fresh medium containing BrdU after $24 \mathrm{~h}$. Subsequently, both cell types were treated with 25 $\mu \mathrm{M}$ etoposide for the indicated times. Results are shown as means $\pm S D$ of at least three independent experiments.

\section{Results}

\section{Etoposide induces the expression of Smad6 gene}

We initially examined how DNA damage-induced signals are interconnected with TGF- $\beta$-mediated cellular responses. In the course of these studies we found that etoposide, a topoisomerase II inhibitor that causes DNA double strand breaks (DSBs), specifically induces the expression of the Smad6 gene. The real-time PCR analysis showed that the transcription of Smad6 in CMT-93 mouse intestinal epithelial cells was maximal 6-12 $\mathrm{h}$ after treatment with etoposide (Figure 1A). Moreover, the expression of Smad6 protein was similar to the

A

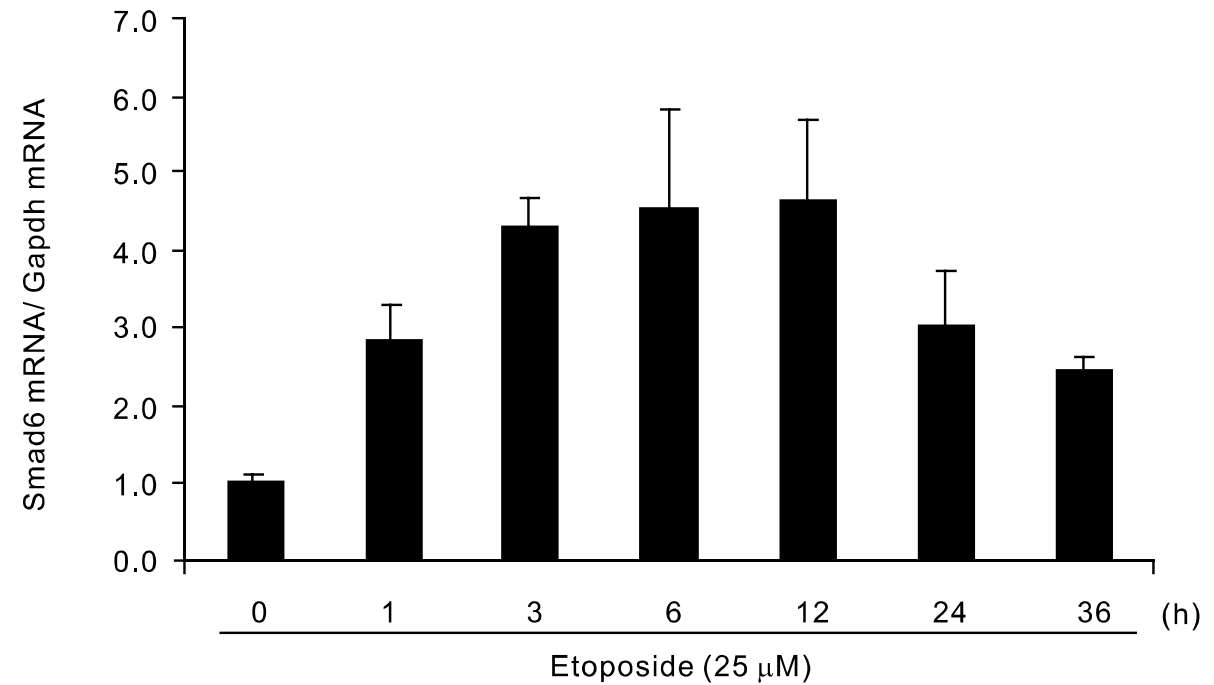

B

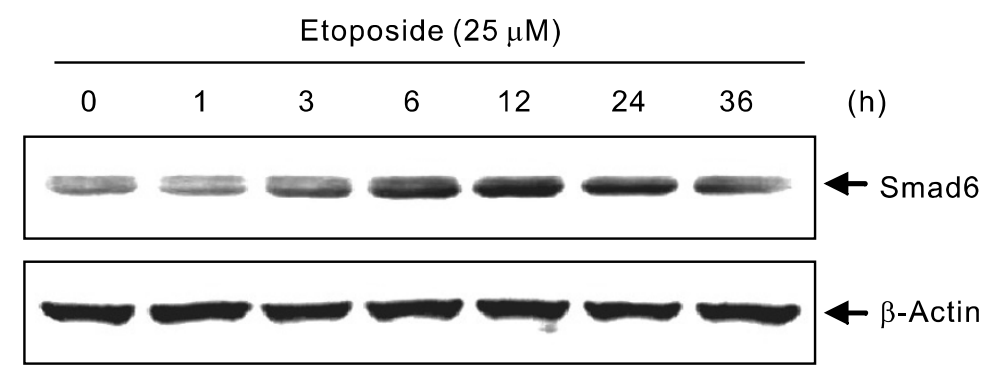

Figure 1. Expression of the Smad6 gene in CMT-93 mouse intestinal epithelial cells is induced by treatment with etoposide. (A) After treatment with etoposide, quantitative real-time RT-PCR analysis of the Smad6 gene was performed as described in the Materials and Methods for the indicated time. GAPDH expression was used for normalization. The results are shown as the mean values $\pm S D$ of three independent experiments. (B) Western blot analysis of Smad6 protein after treatment with etoposide. Actin was used for the loading control. The inset shows a representative result from at least three independent experiments. 
level of Smad6 mRNA (Figure 1B). To our knowledge this is the first report that a DNA damaging agent such as etoposide is able to increase the expression of the Smad6 gene.

\section{A}

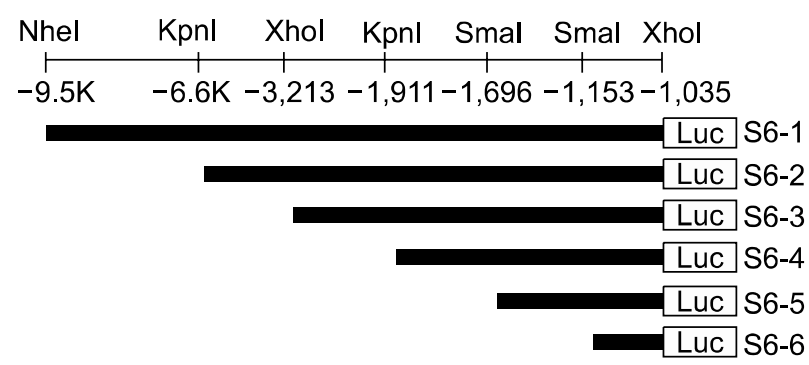

B

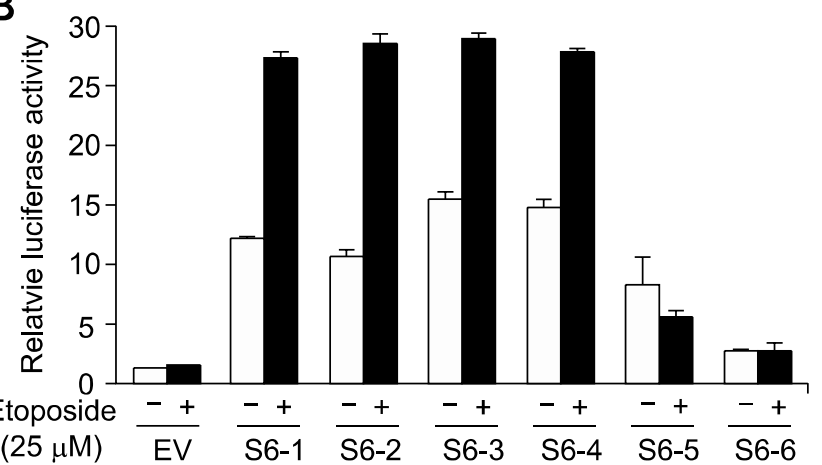

C
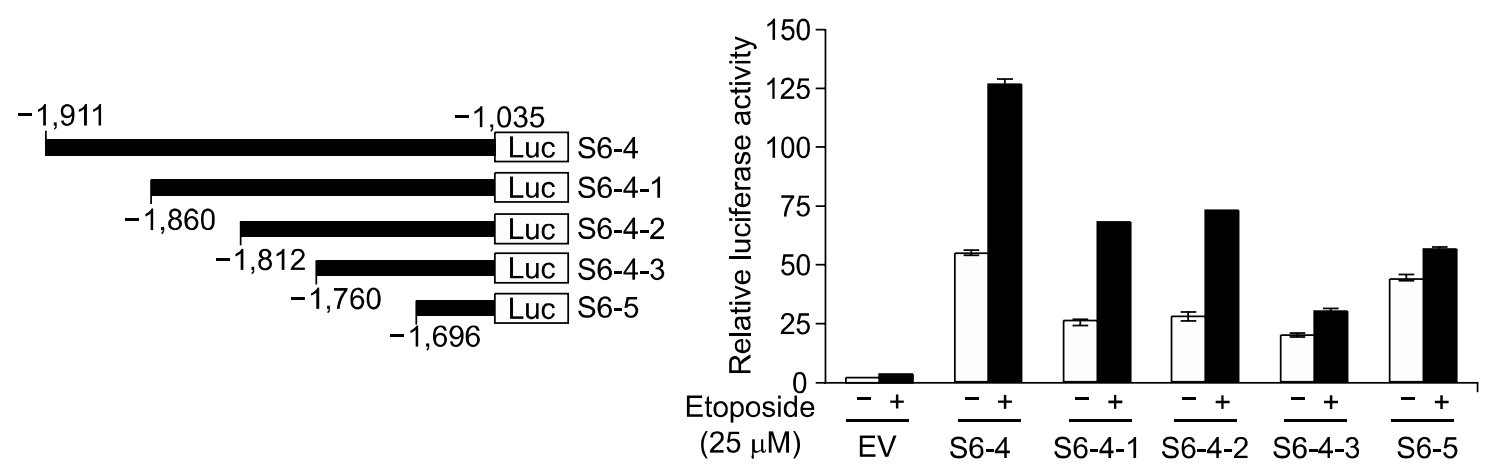

D

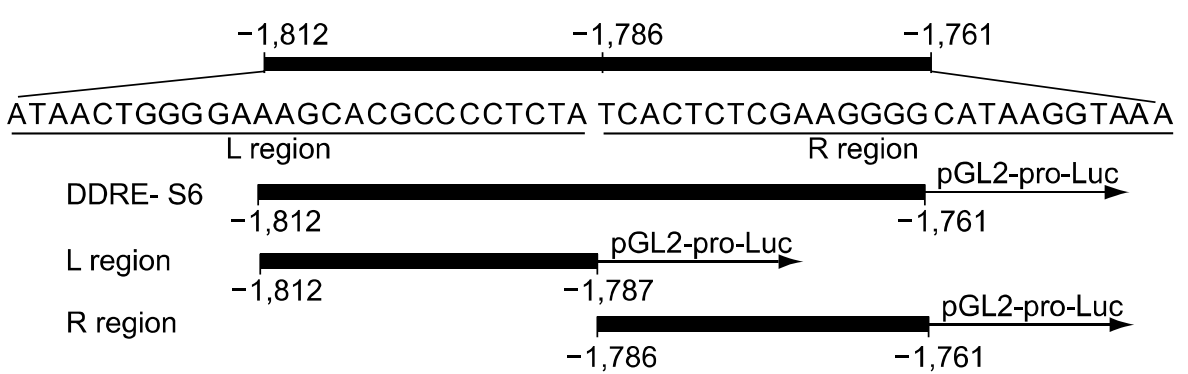

E

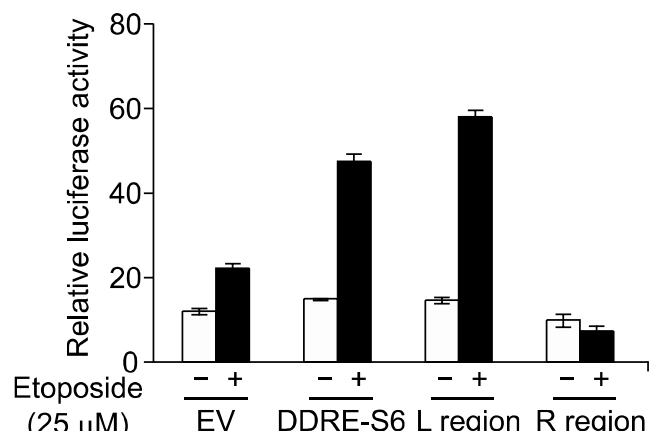

Figure 2. The region from $-1,812$ to $-1,785$ of the Smad6 promoter is required for etoposide-induced transcriptional activation of the Smad6 gene. (A) Schematic representations of serial deletion mutants of the Smad6 promoter. (B) The luciferase activities of serial deletion mutants from the region $-9.5 \mathrm{~kb}$ to $-1,035$ of the Smad6 promoter. EV: empty vector. (C) Schematic representations of subdivided mutants from the region $-1,911$ to $-1,035$ of the Smad6 promoter and their luciferase activities in the presence or absence of etoposide. EV: empty vector. (D) Sequences of the DNA damage-responsible element in the Smad6 promoter (DDRE-S6) and schematic representations of the deletion mutants of the region $-1,812$ to $-1,761$ of the Smad6 promoter. (E) The luciferase activities mediated by DDRE-S6, $L$ region and $R$ region in the presence or absence of etoposide. EV: empty vector. All plasmids in this figure were transiently transfected into CMT-93 cells and treated with or without etoposide for $12 \mathrm{~h}$. The luciferase activities were normalized on the basis of TK-Renilla luciferase expression to adjust for variation in transfection efficiency. All data represent the mean value $\pm S D$ of three independent experiments. 


\section{The cis-acting element from $-1,812$ to $-1,787$ of the Smad6 promoter is required for etoposide-induced transcriptional activation of the Smad6 gene}

We next investigated how the expression of the Smad6 gene is up-regulated upon treatment with etoposide. Our results showed that Smad6 expression is up-regulated at the transcriptional level (Figure 1), and thus promoted us to examine Smad6 promoter activity in the presence of etoposide. Therefore, serial deletion mutants of the mouse Smad6 promoter linked to a reporter gene were transfected into CMT-93 cells and subsequently treated with etoposide. As shown in Figure $2 A$ and $B$, the full-length promoter of the mouse Smad6 gene, designated S6-1, was significantly activated by etoposide treatment. However, when the region from $-1,911$ to $-1,696$ was deleted, induction of the activity of the Smad6 promoter by

A

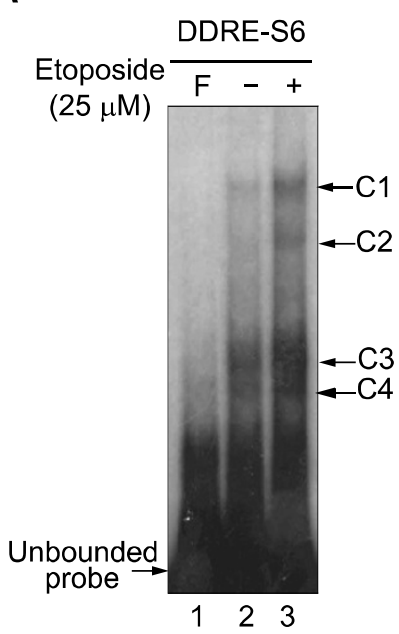

B

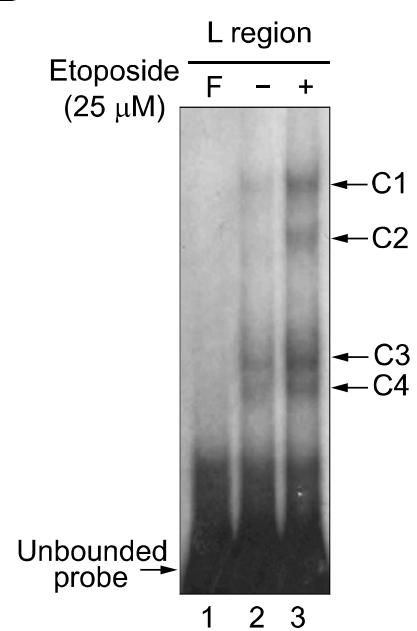

C

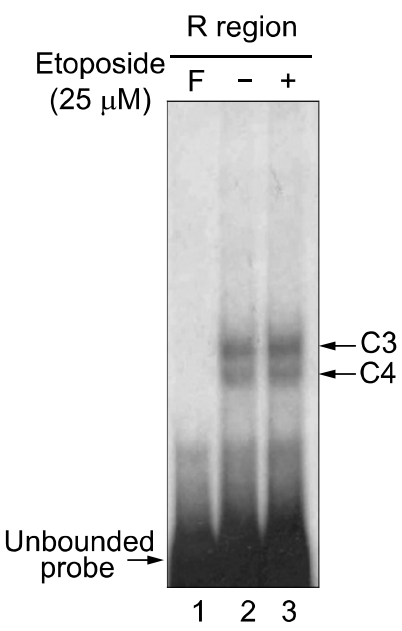

D

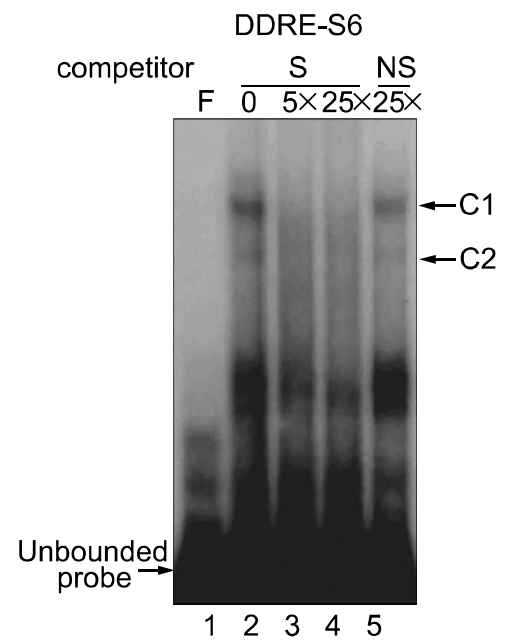

$E$

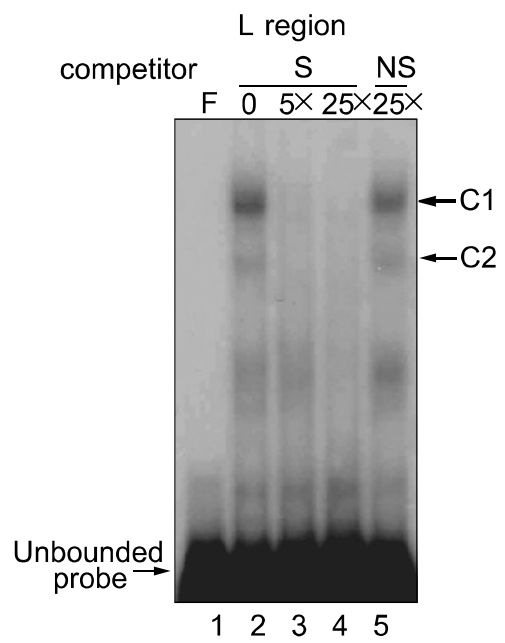

etoposide was reduced compared with the other deletion mutants (Figure 2B). These results indicate that the region from $-1,911$ to $-1,696$ is required for the induction of the Smad6 promoter upon etoposide treatment. To reveal which sequences of this region are involved in etoposideinduced activation of Smad6 promoter, we divided the region from $-1,911$ to $-1,696$ and constructed three serial deletion mutants of the Smad6 promoter, S6-4-1, S6-4-2, and S6-4-3 (Figure 2C). Deletion of the region from $-1,812$ to $-1,760$ abolished etoposide-induced activation of the Smad6 promoter (Figure 2C), demonstrating that this region is required for the activation of the Smad6 gene by etoposide-induced DNA damage.

We further verified that the $51 \mathrm{bp}$ region from $-1,812$ to $-1,760$, designated DDRE-S6 (DNA damage response element in Smad6 promoter), acts as a cis-acting element for the etoposide-
Figure 3. Etoposide increases the specific DNA-binding proteins bound to the region from $-1,812$ to $-1,785$ (L region). Electrophorectic mobility shift assays (EMSA) were performed with the labeled double-stranded oligonucleotides, designated DDRE-S6 (A), L region $(B)$, and $R$ region $(C)$, respectively, and nuclear extracts of CMT-93 cells treated without (lane 2) or with (lane 3) etoposide. Lane 1: free probe. Competition assays were performed with the labeled DDRE-S6 (D) and L region (E) and nuclear extracts of etoposide-treated CMT-93 cells according to the indicated molar ratios of cold competitors. The unlabeled oligonucleotides with the DDRE$S 6$ and $L$ region were used as specific competitors (S), respectively, whereas double-stranded oligonucleotides containing NF- $\mathrm{KB}$ binding sites were used as nonspecific competitors (N). Lane 1; free probe. Lane 2; no competitor. The data are representative results of at least three independent experiments. 
induced activation of the Smad6 promoter. The DDRE-S6 and $L$ and $R$ regions of DDRE-S6, shown in Figure 2D, were cloned into pGL2-pro reporter plasmids. These newly constructed plasmids were transfected into CMT-93 cells and subsequently treated with etoposide. As shown in Figure 2E, the wild type DDRE-S6 region was activated by etoposide treatment. Interestingly, etoposide treatment could not activate the $\mathrm{R}$ region, but did activate the $L$ region. This indicates that the $L$ region, which comprises $26 \mathrm{bp}$, is required for the activation of the Smad6 promoter by etoposideinduced DSBs and implies that distinct DNA binding proteins bound to the $L$ region are specifically induced by etoposide treatment.

\section{Etoposide increases DNA binding proteins specific for the cis-acting element from $-1,812$ to $-1,787$ of the Smad6 promoter}

In order to identify the DNA binding proteins associated with the $L$ region, EMSA was performed with ${ }^{32} \mathrm{P}$-labeled double-stranded oligonucleotides of the $L$ and $R$ region, as well as the DDRE-S6 region. As shown in Figure $3 A$ and $B$, DNA binding proteins $c 1$ and $c 2$, which bound to the $L$ and DDRE regions, were significantly increased upon treatment with etoposide. These complexes (c1 and $c 2$ ) were not detected when the $R$ region was used for EMSA (Figure 3C). These results were consistent with the etoposide-induced activation of the $L$ and DDRE region-fused reporter genes shown in Figure 2E. In addition, competition assays revealed that the DNA-binding proteins, c1 and $c 2$, are specific to the DDRE-S6 and L regions (Figure 3D and E). Therefore, our results strongly suggest that etoposide, a topoisomerase II inhibitor, significantly up-regulates the expression of the Smad6 gene by increasing DNA binding proteins specific for the $L$ region (from $-1,812$ to $-1,787)$ of the Smad6 promoter.

\section{The increased expression of the Smad6 gene by etoposide is required for the G1 to $S$ phase transition of the cell cycle}

Etoposide induces double strand breaks (DSBs), thus triggering cell cycle arrest and apoptosis (Kaufmann, 1998; Sleiman and Stewart, 2000; Blass et al., 2002; Clifford et al., 2003). However, the mechanism of cell cycle arrest induced by etoposide is still controversial and probably depends on cell type. Some reports indicate that cells accumulate in the $\mathrm{G} 1-\mathrm{S}$ phase of the cell cycle (Blass et al., 2002), whereas others show arrest in the G2-M phase (Sleiman and Stewart, 2000; Clifford et al., 2003). To investigate the role of Smad6 expression in the cell cycle, we first examined whether CMT-93 cells expressing Smad6 are arrested by etoposide treatment. As shown in Figure 4A, CMT-93 cells predominantly accumulated in the G2-M phase of the cell cycle. Next, to reveal the function of the Smad6 gene in etoposideinduced cell cycle arrest, we synchronized Smad6expressing (CMT-93-pU6PL) and Smad6-knockdown (CMT-93-siS6) cells using a double thymidine block and released them into etoposide. Interestingly, Smad6-knock-down cells transiently accumulated in the $\mathrm{G} 1$ phase of the cell cycle, in contrast to Smad6-expressing CMT-93 cells (Figure 4B). In addition, the analysis of the rate of cell proliferation using incorporation of BrdU, which is taken up in place of thymidine during the $S$ phase of the cycling cell, showed that endogenous inhibition of the Smad6 gene caused a decreased rate of incorporation of BrdU (Figure 4C). These results imply that increased expression of Smad6 is involved in the initiation of the cell cycle during the response to etoposide-induced DNA damage. To elucidate these phenomena, we investigated the expression of p21 protein, a cyclin-dependent protein kinase (CDK) inhibitor, in Smad6-expressing and Smad6-knock-down CMT-93 cells after treatment with etoposide. As shown in Figure 4D, expression of p21 protein was rapidly increased at 1-6 $\mathrm{h}$ in Smad6-knock-down cells, compared with control cells. These results strongly suggest the possibility that Smad6 expression induced by etoposide is involved in the initiation of the cell cycle by regulating the expression of CDK inhibitors such as p21. However, it is still unclear whether Smad6 expression regulates the stability of CDK inhibitors at the post-translational level.

\section{Discussion}

We have demonstrated here that etoposide, which causes DSBs, specifically induces the Smad6 gene by increasing the levels of distinct DNA binding proteins that bind to the $L$ region (from $-1,812$ to $-1,787)$, and that increased expression of Smad6 protein contributes to the initiation of the $\mathrm{G} 1$ to $S$ cell cycle transition.

Interestingly, extracellular stimuli or agents that induce the expression of the Smad6 gene have not been reported as frequently as those of the Smad7 gene. Several reports indicate that laminar shear stress or TPA regulate the expression of the Smad6 gene (Topper et al., 1997; Tsunobuchi et al., 2004). In this study, we found that etoposide, which causes DSBs, induces the Smad6 gene. 
A

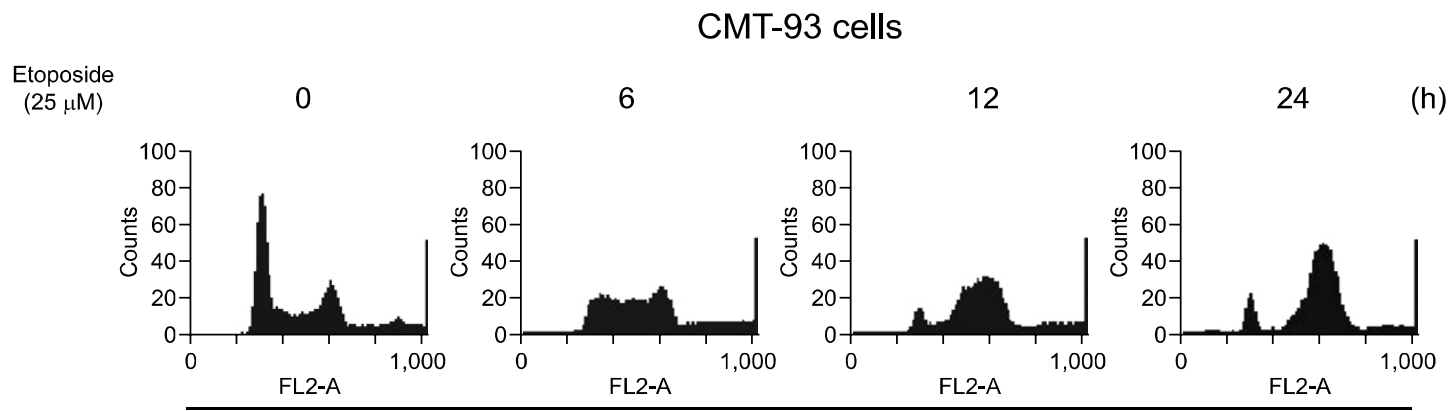

Relative DNA contents

B

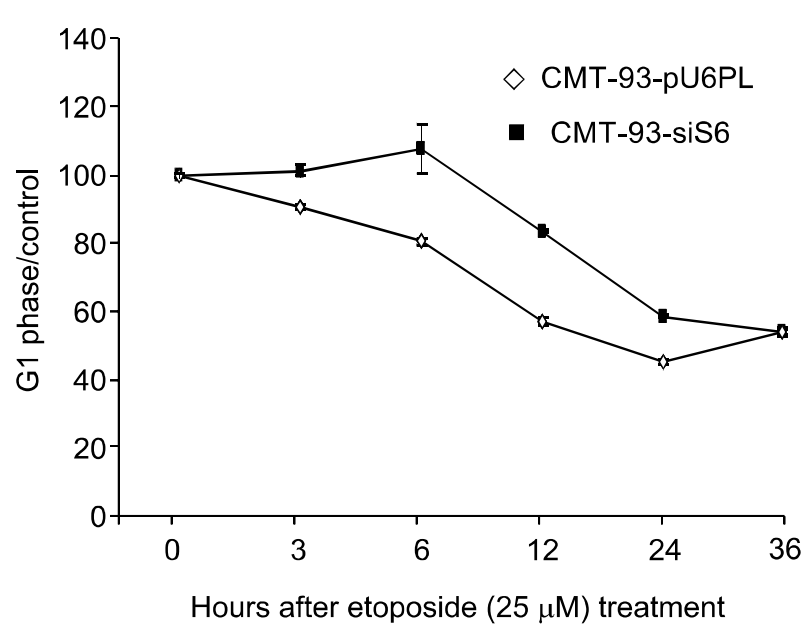

C

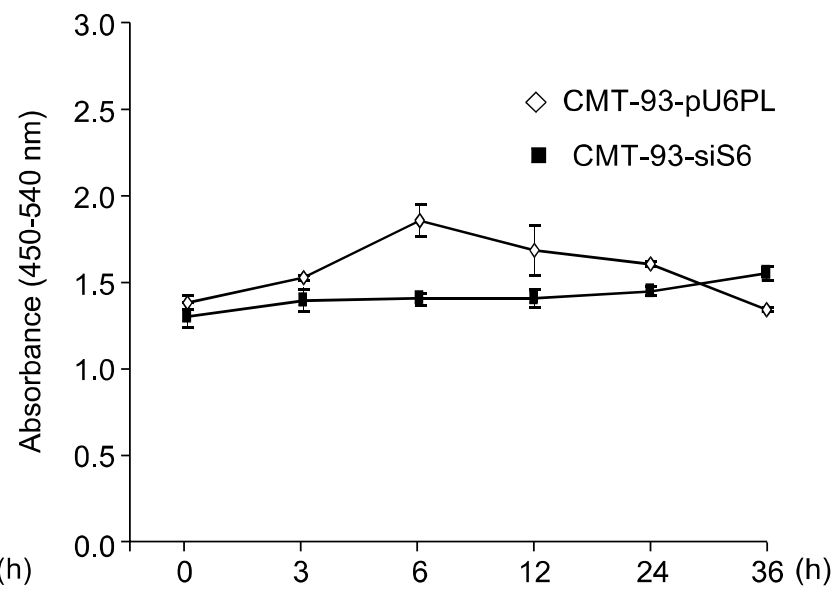

Hours after etoposide $(25 \mu \mathrm{M})$ treatment

D

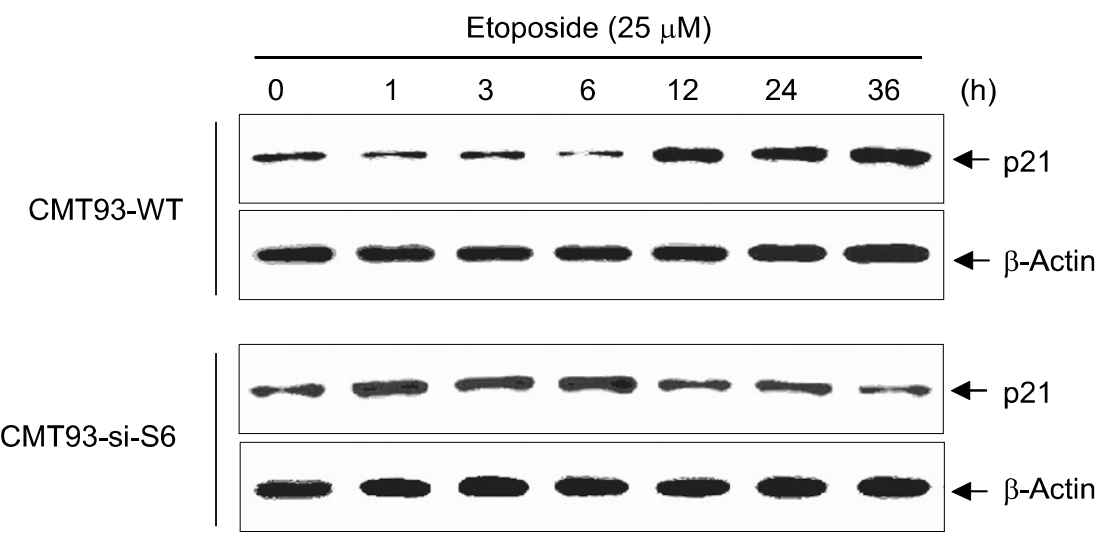

Figure 4. Endogenous inhibition of the Smad6 gene by Smad6 siRNA induces changes in etoposide-induced G1-S cell cycle transition and BrdU incorporation. (A) Cell cycle analysis of Smad6-expressing CMT-93 wild type cells upon treatment with etoposide. The inset shows representative results of at least three independent experiments. (B) Analysis of the etoposide-induced accumulation of G1 phase cells in CMT-93 cells either expressing Smad6 (CMT-93-pU6PL) or stably expressing Smad6 siRNA (CMT-93-siS6). Cells were synchronized by double thymidine block, released into etoposide and harvested at the indicated time points. Cell cycle distribution was checked by flow cytometry after staining with propidum iodide. (C) Analysis of etoposide-induced BrdU incorporation into CMT-93 cells either expressing Smad6 (CMT-93-pU6PL) or stably expressing Smad6 siRNA (CMT-93-siS6). BrdU incorporation was analyzed as described in the Materials and Methods. The results ( $B$ and $C$ ) are shown as the mean $\pm S D$ of three independent experiments. (D) Western blot analysis of etoposide-induced p21 gene expression in CMT-93 cells either expressing Smad6 (CMT-93-pU6PL) or stably expressing Smad6 siRNA (CMT-93-siS6). Actin was used for the loading control. The insets show representative results of at least three independent immunoblotting experiments. 
Furthermore, DNA damage caused by gamma irradiation also increased the expression of the Smad6 gene (data not shown). The finding that DNA damaging agents such as etoposide induce the expression of the Smad6 gene may provide important clues to the unidentified function of Smad6. In addition, the finding that increased expression of Smad6 is required for the initiation of the $\mathrm{G} 1$ to $S$ cell cycle transition suggests that the Smad6 protein has novel function(s) in DNA damage-induced signal transduction cascades. In particular, our findings raise the possibility that Smad6 is an important modulator of p21 protein, which is involved in the machinery of the cell cycle, although the biochemical mechanisms remain unknown.

We have also shown that etoposide induces the transcription of the Smad6 gene by increasing specific DNA-binding proteins, which bind to the region from $-1,812$ to $-1,785$ of the Smad6 promoter. It has been reported that the Smad6 promoter contains GC-rich Smad1/5 binding elements and the OSE sites bound to the Runx2 transcription factor (Ishida et al., 2000; Wang et al., 2007). However, the element responsible for etoposide-induced Smad6 transcription identified in this study is different from the cis-acting elements in the Smad6 promoter described previously. Therefore, it will be worthwhile to characterize the proteins that bind to the region from $-1,812$ to $-1,785$, designated $c 1$ and $c 2$.

The most important finding of this study is the demonstration that cellular responses caused by DNA damage signals are related to expression of the Smad6 gene. These findings suggest that Smad6 has a distinct cellular function as well as being an antagonist for TGF- $\beta / B M P$ signaling. Therefore, further biochemical study of etoposideinduced Smad6 transcription and the subsequent cell cycle transition may provide new insight into the novel function of Smad6, in addition to its action as an inhibitory Smad.

\section{Acknowledgements}

We thank Dr. Miyazono for Smad6 promoter-reporter plasmids, and Kyung-Chul Choi, and Hyo Kyoung Choi for technical assistances. This work was supported by a Korea Research Foundation grant (R08-2003-000-10077-0) and in part by a Korea Science and Engineering Foundation (KOSEF) grant (ROA-2007-000-20047-0) funded by the Korea Government.

\section{References}

Bitzer M, von Gersdorff G, Liang D, Dominguez-Rosales A,
Beg $A A$, Rojkind $M$, Bottinger EP. A mechanism of suppression of TGF-beta/SMAD signaling by NF-kappa B/RelA. Genes Dev 2000;14:187-97

Blass M, Kronfeld I, Kazimirsky G, Blumberg PM, Brodie C. Tyrosine phosphorylation of protein kinase Cdelta is essential for its apoptotic effect in response to etoposide. Mol Cell Biol 2002;22:182-95

Choi KC, Lee YS, Lim S, Choi HK, Lee CH, Lee EK, Hong S, Kim IH, Kim SJ, Park SH. Smad6 negatively regulates interleukin 1-receptor-toll-like receptor signaling through direct interaction with the adaptor Pellino-1. Nat Immunol 2006;7:1057-65

Clifford B, Beljin M, Stark GR, Taylor WR. G2 arrest in response to topoisomerase II inhibitors: the role of p53. Cancer Res 2003;63:4074-81

Ebisawa T, Fukuchi M, Murakami G, Chiba T, Tanaka K, Imamura T, Miyazono K. Smurf1 interacts with transforming growth factor-beta type I receptor through Smad7 and induces receptor degradation. J Biol Chem 2001;276: 12477-80

Hayashi H, Abdollah S, Qiu Y, Cai J, Xu YY, Grinnell BW, Richardson MA, Topper JN, Gimbrone MA Jr, Wrana JL, Falb D. The MAD-related protein Smad7 associates with the TGFbeta receptor and functions as an antagonist of TGFbeta signaling. Cell 1997;89:1165-73

Imamura T, Takase M, Nishihara A, Oeda E, Hanai J, Kawabata M, Miyazono K. Smad6 inhibits signalling by the TGF-beta superfamily. Nature 1997;389:622-26

Ishida W, Hamamoto T, Kusanagi K, Yagi K, Kawabata M, Takehara K, Sampath TK, Kato M, Miyazono K. Smad6 is a Smad1/5-induced smad inhibitor. Characterization of bone morphogenetic protein-responsive element in the mouse Smad6 promoter. J Biol Chem 2000;275:6075-9

Kaufmann SH. Cell death induced by topoisomerasetargeted drugs: more questions than answers. Biochim Biophys Acta 1998;1400:195-211

Kavsak P, Rasmussen RK, Causing CG, Bonni S, Zhu H, Thomsen GH, Wrana JL. Smad7 binds to Smurf2 to form an E3 ubiquitin ligase that targets the TGF beta receptor for degradation. Mol Cell 2000;6:1365-75

Kwak HJ, Kim SH, Yoo HG, Park SH, Lee CH. Jun activation domain-binding protein 1 is required for mitotic checkpoint activation via its involvement in hyperphosphorylation of 53BP1. J Cancer Res Clin Oncol 2005;131:789-96

Lee EJ, Kim SH, Kwark YE, Kim J. Heterogeneous nuclear ribonuclear protein $\mathrm{C}$ is increased in the celecoxib-induced growth inhibition of human oral squamous cell carcinoma. Exp Mol Med 2006;38:203-9

Lee EJ, Choi EM, Kim SR, Park JH, Kim H, Ha KS, Kim YM, Kim SS, Choe M, Kim JI, Han JA. Cyclooxygenase-2 promotes cell proliferation, migration and invasion in U2OS human osteosarcoma cells. Exp Mol Med 2007a;39:469-76

Lee EK, Lee YS, Han IO, Park SH. Expression of Caveolin-1 reduces cellular responses to TGF-beta1 through downregulating the expression of TGF-beta type II receptor gene in NIH3T3 fibroblast cells. Biochem Biophys Res Commun 


\section{7b;359:385-90}

Murakami G, Watabe T, Takaoka K, Miyazono K, Imamura $\mathrm{T}$. Cooperative inhibition of bone morphogenetic protein signaling by Smurf1 and inhibitory Smads. Mol Biol Cell 2003;14:2809-17

Nakao A, Afrakhte M, Moren A, Nakayama T, Christian JL, Heuchel R, Itoh S, Kawabata M, Heldin NE, Heldin CH, ten Dijke P. Identification of Smad7, a TGF-beta-inducible antagonist of TGF-beta signalling. Nature 1997;389:631-5

Park SH, Birchenall-Roberts MC, Yi Y, Lee BI, Lee DK, Bertolette DC, Fu T, Ruscetti F, Kim SJ. Mechanism of induction of transforming growth factor-beta type II receptor gene expression by $\mathrm{v}-\mathrm{Src}$ in murine myeloid cells. Cell Growth Differ 2001;12:9-18

Park SH. Fine tuning and cross-talking of TGF-beta signal by inhibitory Smads. J Biochem Mol Biol 2005;38:9-16

Patil S, Wildey GM, Brown TL, Choy L, Derynck R, Howe PH. Smad7 is induced by CD40 and protects WEHI 231 B-lymphocytes from transforming growth factor-beta-induced growth inhibition and apoptosis. J Biol Chem 2000; 275:38363-70

Robert J, Larsen AK. Drug resistance to topoisomerase II inhibitors. Biochimie 1998;80:247-54

Sleiman RJ, Stewart BW. Early caspase activation in leukemic cells subject to etoposide-induced G2-M arrest: evidence of commitment to apoptosis rather than mitotic cell death. Clin Cancer Res 2000;6:3756-65

Topper JN, Cai J, Qiu Y, Anderson KR, Xu YY, Deeds JD, Feeley R, Gimeno CJ, Woolf EA, Tayber O, Mays GG, Sampson BA, Schoen FJ, Gimbrone MA Jr, Falb D. Vascular MADs: two novel MAD-related genes selectively inducible by flow in human vascular endothelium. Proc Natl Acad Sci USA 1997;94:9314-9

Tsunobuchi $H$, Ishisaki A, Imamura T. Expressions of inhibitory Smads, Smad6 and Smad7, are differentially regulated by TPA in human lung fibroblast cells. Biochem Biophys Res Commun 2004;316:712-9

Ulloa L, Doody J, Massague J. Inhibition of transforming growth factor-beta/SMAD signalling by the interferongamma/STAT pathway. Nature 1999;397:710-3

Wang Q, Wei X, Zhu T, Zhang M, Shen R, Xing L, O'Keefe RJ, Chen D. Bone morphogenetic protein 2 activates Smad6 gene transcription through bone-specific transcription factor Runx2. J Biol Chem 2007;282:10742-8 